\title{
Air embolus revisited - a diagnostic and interventional radiological perspective (bubble trouble and the dynamic Mercedes Benz sign)
}

\author{
D J Emby, MB BCh, FFRad (D) SA \\ K Ho, MB BCh, FCP (SA)
}

Western Deep Levels Hospital, PO Box 8425, Western Levels, 2501

\begin{abstract}
Air embolus has always been a recognised hazard within the practice of diagnostic imaging. This is now, more than ever, the case with the advent of the widespread use of pump injectors for intravenous contrast delivery and the increasing use of percutaneous interventions in the lungs.

The different clinical syndromes associated with air embolus in the systemic venous (right heart) circulation and the systemic arterial (left heart) circulation need to be clearly understood in order to diagnose and treat these conditions in the clinical setting.

This article reviews the topic of air embolus, including diagnosis and treatment, as this specifically relates to the practice of diagnostic and interventional radiology. The article also includes images relating to the depiction of air embolus, with attention drawn to a commonly encountered imaging appearance or sign.
\end{abstract}

\section{Introduction}

In no discipline does the maxim: 'First do no harm', have greater significance than in diagnostic radiology. For a patient to suffer morbidity or even death during a diagnostic procedure is the embodiment of a medical tragedy. The hazards of ionizing radiation and the potential for contrast media to cause life-threatening allergic reactions and nephropathy, have for many years constituted the most well-recognised dangers of non-invasive diagnostic radiological imaging.

Invasive diagnostic procedures such as angiography, carry the risk of adverse events related specifically to the nature of the procedure (and for angiography, include thrombosis, embolisation, dissection and perforation). Invasive diagnostic procedures and interventional radiological procedures fall more within the province of surgery in terms of the risks associated with the procedure. It is generally accepted that all surgical procedures carry some risk.

New technologies have brought new dangers, perhaps the best example being the dangers posed by the super magnets of magnetic resonance imaging (MRI). New technologies have also in certain instances brought with them an increased potential for already-known dangers. In this setting, two developments, namely the advent of the widespread use of pump injectors for intravenous injection of contrast (in association with helical CT scanning); and the increasing number of percutaneous interventions that are being performed within the lungs; make it imperative that the well-known hazard of air embolism should be revisited, in the context of the way in which it pertains to the current practice of diagnostic and interventional radiology.

\section{Pathophysiology}

Central to the understanding of the dangers posed by air embolisation and to the diagnosis and management of air embolus, is an understanding of the 2 different clinical syndromes that occur with air embolus within the right heart circulation, and air embolus within the left heart circulation.

\section{Air within the right heart circulation}

This occurs when air enters the systemic venous circulation.

Air may enter a peripheral vein (and thereby the systemic venous circulation) if the air within the intravenous line of a pump injector or a drip infusion is not properly removed before the intravenous line is attached to an intravenous canula. Similarly, air may enter the systemic circulation if it has not been meticulously removed from the vascular tubing of a haemodialysis circuit. ${ }^{1}$

There are a number of other well-recognised mechanisms whereby air may enter the systemic venous system. Air may enter the vascular system through lacerations to major veins, due to the sucking effect of the negative intrathoracic pressure created by inspiration (sucking wounds) This is also a well-recognised danger during thoracic and cervical surgery. It should also be noted that a central venous catheter, which becomes disconnected, provides a similar potential opportunity for air to be sucked into the central venous system. ${ }^{2}$ The danger of air entering the vascular system through incision of a dural sinus is a well recognised hazard of intracranial surgery, particularly during craniotomy with the patient in the sitting position. ${ }^{3}$

Gas may also enter the venous system following air insufflation of body cavities for endoscopic surgery. ${ }^{4}$ It is also well documented that air may enter the veins of the myometrium during pregnancy and after childbirth.,

Small volumes of air entering the right atrium from the systemic venous system, generally pass through the right atrium and right ventricle into the pulmonary arterial circulation. The lungs appear to have a large capacity to compensate for air embolus within the pulmonary arterial circulation. The lungs can filter micro bubbles if these enter the pulmonary arterial circulation at a slow rate.

Larger volumes of air accumulating within the pulmonary arterial circulation cause right ventricular strain. Pulmonary arterial pressure increases and increased resistance to right ventricular outflow causes decreased pulmonary venous return. This results in diminished cardiac output and if allowed to continue, ultimately leads to systemic cardiovascular collapse. ${ }^{8}$

Large volumes of air, which rapidly enter the right heart can cause foaming within the right ventricle, so that no liquid blood is available 
for propulsion into the main pulmonary artery. ${ }^{9}$ In such circumstances circulatory collapse would rapidly ensue.

Both the volume of gas and the rate of infusion appear to be important. A large volume of $50 \mathrm{ml}$ or greater infused at a rapid rate is potentially fatal. ${ }^{10}$

Small volumes and slow rates can be tolerated. In dogs the lung can cope with up to approximately $0.3 \mathrm{ml}$ per kilogram per minute. ${ }^{7} \mathrm{~A}$ few small air bubbles in the injector tubing are therefore unlikely to produce any adverse effects on the right heart circulation.

\section{Air within the left heart circulation}

This occurs when air enters the systemic arterial circulation.

Air bubbles may be injected directly into a systemic artery during angiographic arterial catheterisation. Any cardiac surgical procedure that is performed under extracorporeal bypass can cause arterial gas embolism. ${ }^{11}$

Importantly, in the iatrogenic context, percutaneous interventions in the lung parenchyma may allow air bubbles to enter the pulmonary veins. From there the air bubbles travel via the left atrium and left ventricle into the systemic arterial circulation, causing systemic air embolus. There are now numerous reports in the literature describing systemic arterial air embolisation following percutaneous procedures in the lung. ${ }^{12-20}$

A further, indirect mechanism of systemic arterial air embolus is recognised. Where there is a connection between the right and left heart circulation, air emboli may bypass the filtering mechanism of the lungs and pass directly from the right heart circulation to the left heart circulation. This is known as paradoxical embolism. The classic example of this phenomenon is where there is a patent foramen ovale present. In this setting, air that enters the systemic venous system has the potential to cause systemic arterial embolisation. Some estimates suggest that the incidence of a patent foramen ovale in the general population may be as high as $30 \%{ }^{8}$

Any discussion of arterial air embolism would not be complete without mention of the well-known association between underwater diving and air embolus (decompression sickness or caisson disease). With rapid ascent from depth, nitrogen gas, which has become dissolved in the body tissues, including the blood plasma, comes out of solution to form bubbles of gas within tissues and within the circulatory system. ${ }^{9}$

Air bubbles within the arterial system behave in a similar way to solid emboli and cause occlusion of end arteries, leading to tissue infarction. In the cerebral and coronary circulations, this has been associated with death. ${ }^{19,21,22}$

\section{Discussion}

\section{Air embolus in the systemic venous system}

Despite meticulous technique, small air bubbles may occasionally enter the systemic venous system in association with injection of intravenous contrast by a pressure injector. Small venous air emboli from intravenous lines probably in fact, occur often. ${ }^{23}$

In a series reported by Groell et al. ${ }^{24}$, small air embolism was visible in 10 out of 208 patients (4.8\%) who underwent computed tomography (CT) scan after insertion of a peripheral venous cannula. The small air emboli were most commonly seen in the pulmonary trunk (6 patients), followed by the right ventricle ( 2 patients). In the remaining 2 patients, the small air embolus was detected in the right atrium in 1 and in the left brachiocephalic vein in the other. The embolism was asymptomatic in all the patients.

Air loculations within a pulsating major mediastinal vascular structure frequently demonstrate a tri-radiate appearance (Figs 1 - 3). We call this the dynamic Mercedes Benz sign.

Pulsation offshoot artefact from central venous catheters is a wellrecognised phenomenon, and although variable in appearance, is characteristically also seen as a tri-radiate configuration (dynamic Mercedes Benz sign) (Fig. 4). The similarity in the pattern of offshoot artefact between intravascular air bubbles and intravascular cannulas, is clearly shown in these images.

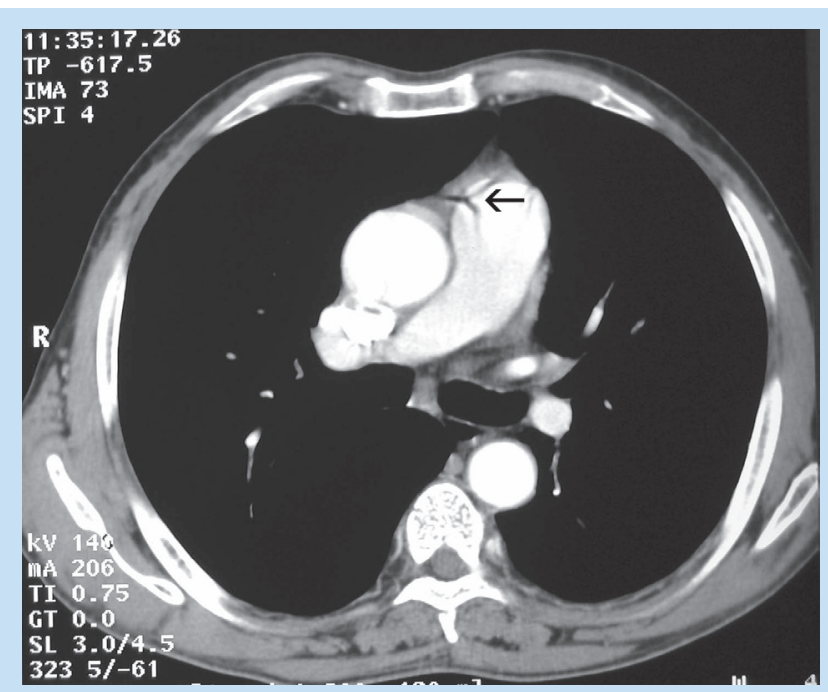

Fig. 1. Axial CT slice through level of main pulmonary outflow tract showing tri-radiate offshoot artifact (due to pulsation) from air bubble in main pulmonary outflow tract (dynamic Mercedes Benz sign) (arrow). This could be mistaken for an intimal flap.

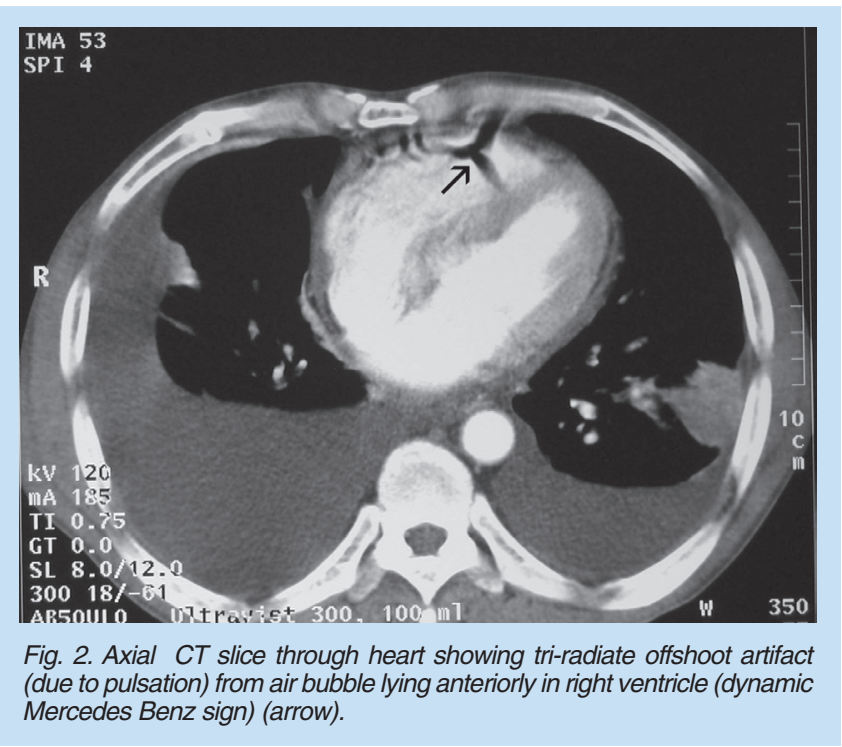




\section{REVIEW ARTICLE}
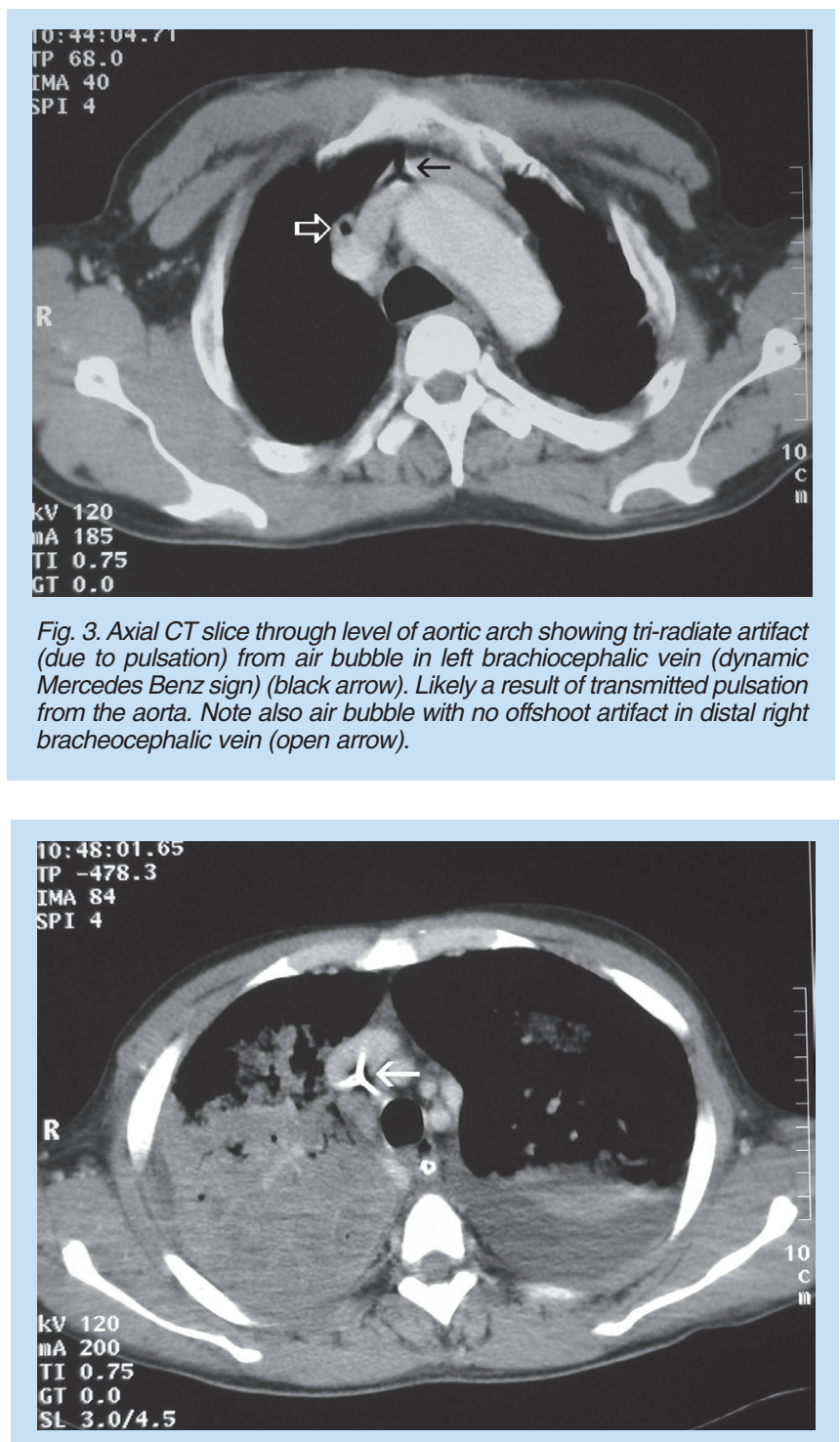

Fig. 4. Axial CT slice through upper thorax showing typical tri-radiate offshoot artifact (due to pulsation) from the central venous catheter in the superior vena cava (dynamic Mercedes Benz sign) (arrow).

When the tri-radiate offshoot artefact is not seen, diminished (or even absent) pulsation is suggested (Figs 5 and 6 ).

The tri-radiate streak offshoot artefact from small air emboli can be mistaken for an intimal flap (Fig. 1), if the observer is not familiar with this appearance.

Small air loculations may occasionally be detected within the veins and venous pathways of the head and neck, particularly the cavernous sinuses, in patients with intravenous cannulation. (Figs $7 \mathrm{a}$ and b). In the absence of infection, trauma or previous surgery, and if there are no systemic features of venous air embolus, these small air bubbles represent only minimal venous air embolism, and are of no clinical significance..$^{23,25}$

Recognition of air embolus on CT scan images is important for a number of reasons: (i) so that the typical appearance of small air

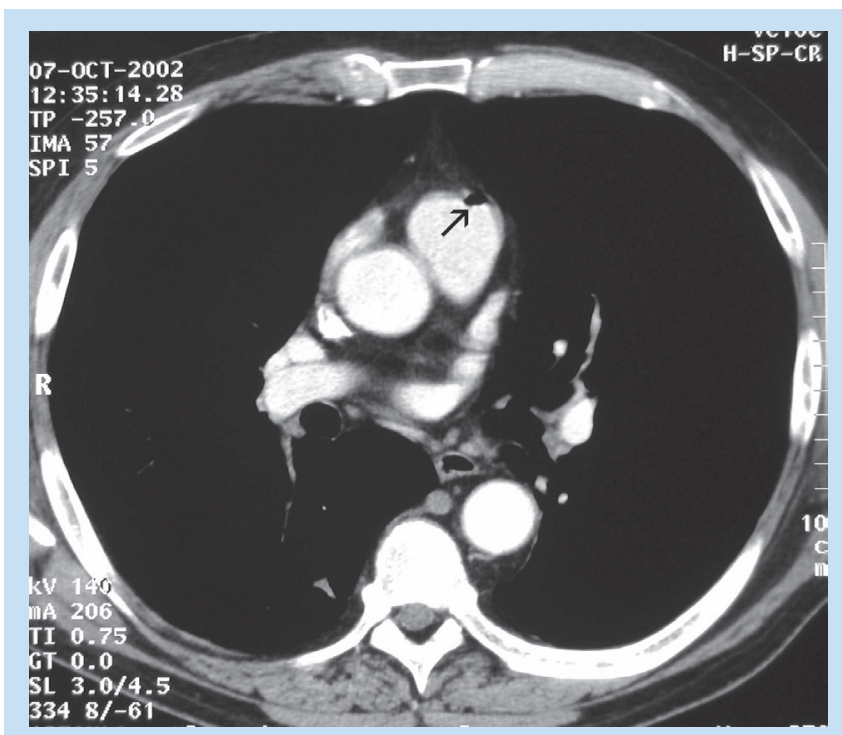

Fig. 5. Axial CT slice through main pulmonary outflow tract showing air bubble situated anteriorly in main pulmonary outflow tract with no offshoot artifact (arrow).

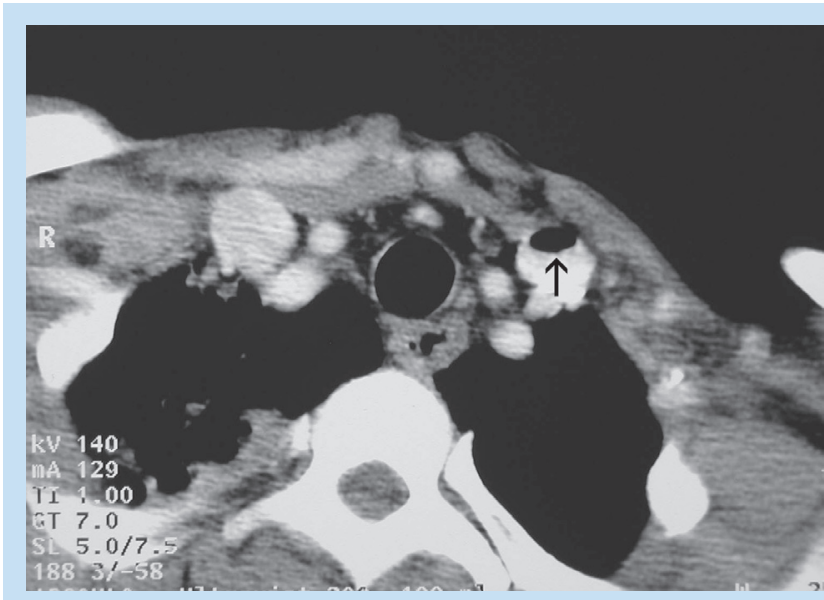

Fig. 6. Axial CT slice through level of thoracic inlet showing large air bubble, without pulsation offshoot artifact, in left internal jugular vein (arrow).

bubbles in the central vascular system is identified and not mistaken for other pathology; (ii) so that where small air emboli are detected, an audit of the pressure injection equipment and technique can be carried out in order to avoid the potential injection of larger (more dangerous) volumes of air; (iii) so that appropriate measures can be taken to treat air embolus, should larger volumes of air be detected on the CT scan images or should the patient display clinical signs or symptoms of air embolus; and (iv) finally, so that those concerned can be reassured of the generally benign nature of small volumes air within the systemic venous system.

A large iatrogenic venous air embolism due to a pump injection with intravenous contrast for CT scan is described by Shigekedi et al. ${ }^{26}$ Images through the heart showed a large amount of air in the right ventricle. The patient was given oxygen and placed in the left lateral decubitus position. He suffered no adverse effects. 


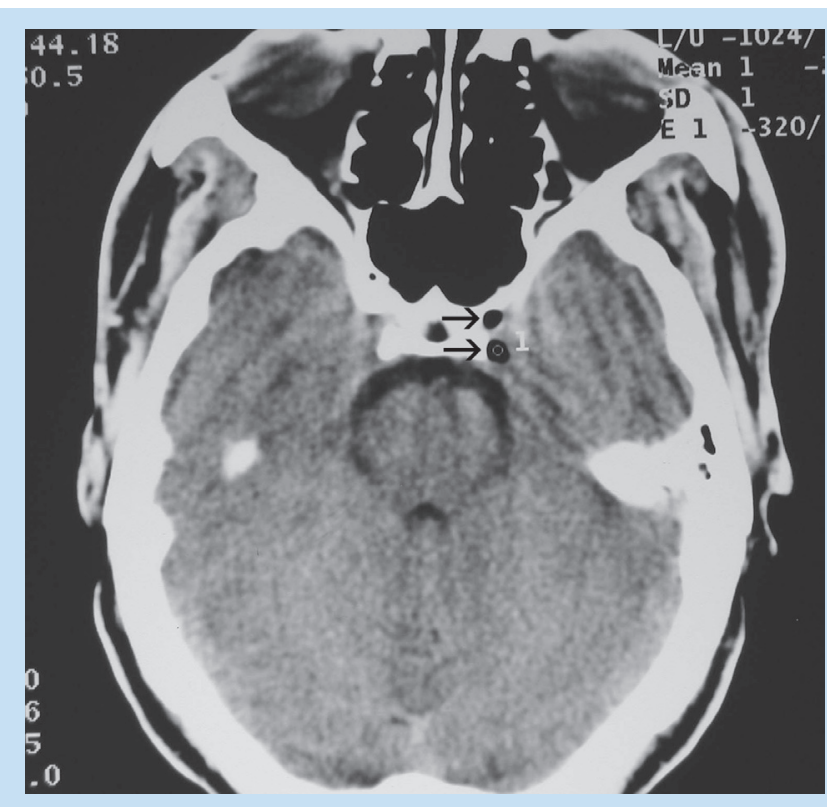

Fig. 7a. Axial CT slice through level of floor of sella turcica showing air loculations in left cavernous sinus (arrows).

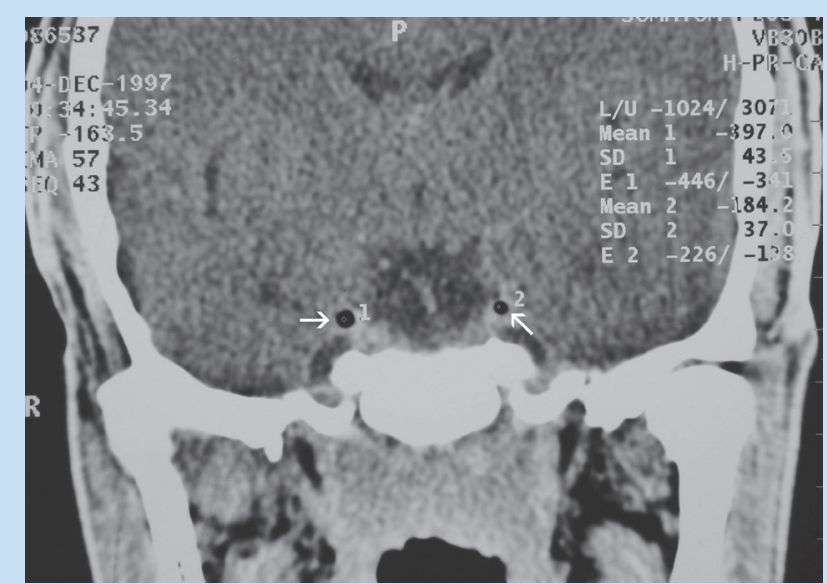

Fig. 7b. Direct coronal CT slice through cavernous sinuses showing bilateral small air loculations within cavernous sinuses (arrows).

\section{Air embolus in the systemic arterial system}

There are 2 mechanisms by which air may enter the pulmonary veins and cause systemic arterial embolus during percutaneous interventions in the lungs.

The first of these mechanisms is by direct puncture of a pulmonary vein with a hollow bore needle that is open to the atmosphere. The negative intrathoracic pressure during inspiration may then suck air through the needle into the vein. Careful technique, ensuring that the hollow bore of the needle is sealed at all times, should avoid this.

The second mechanism by which air may enter the pulmonary veins is by the inadvertant creation of a fistula between a small airway and a pulmonary vein. Clearly, the operator has less control over the potential creation of such a fistulous connection. This is considered to be the mechanism by which systemic air embolisation occurred in the recently reported case by Ashizawa et al. ${ }^{13,27}$
Radiofrequency ablation is believed to generate microbubbles around the radiofrequency probe, which flow into the draining venous circulation. Yamamoto et al. ${ }^{28}$ investigated the possibility that microbubbles generated during radiofrequency ablation of lung tumours might be distributed via the pulmonary veins and left heart to the systemic arterial circulation. They found evidence of microbubble generation but no evidence of cerebral infarction. Among the reasons discussed for the lack of any adverse effect, is the fact that the microbubbles generated by radiofrequency ablation appeared to be extremely small, on average less than one-quarter of the size of the microbubbles used as sonographic contrast agents ( $3-8 \mu \mathrm{mm}$ verses approximately $35.5 \mu \mathrm{mm}$ ).

It should be noted that despite the reported incidence of the presence of a patent foramen ovale being as high as 30\% in the general population, paradoxical embolus appears to be rare. This is in spite of the seemingly common occurrence of infusion of a few small air bubbles, in association with intravenous lines. The risk of potential paradoxical arterial embolus from small volumes of systemic venous air embolus can probably be regarded as remote, although the risk with larger volumes of air should be considered significant.

In a recumbent patient the intra-atrial pressure gradient is from left to right, so that even if a small patent foramen ovale is present, the physiological status quo would tend to prevent paradoxical embolus. With systemic venous air embolus large enough to cause pulmonary arterial hypertension, an associated rise in right atrial pressure would predispose to right-to-left shunting through a patent foramen ovale. It is also of note that the use of the sitting position in neurosurgery (in addition to predisposing to direct entry of air into a dural sinus), inherently predisposes neurosurgical patients to paradoxical air embolism, since the normal intra-atrial pressure gradient frequently becomes reversed in the upright position. ${ }^{29}$

\section{Signs and symptoms of air embolus}

Clinical symptoms of air embolism are evident when a significant amount of air is introduced into the circulation, and thus most cases of minor air embolism are asymptomatic. ${ }^{30}$ In addition, symptoms and signs may be nonspecific, often present in other medical conditions such as pulmonary embolism, pneumothorax, cardiogenic and anaphylactic shock and cerebrovascular accidents, ${ }^{31}$ and so a high index of suspicion is required should these symptoms occur in a patient in the 'at risk' clinical setting.

\section{Venous air embolism}

Sudden onset of dyspnoea and chest pain occur in significant venous air embolism and this accompanies signs of tachypnoea, wheezes, rales, tachycardia and hypotension. Signs of right-sided heart failure may be present and cardiac auscultation may reveal a 'mill-wheel murmur'; a splashing sound audible due to air in the right ventricle. ${ }^{8}$

Doppler sonography can be used as a sensitive and practical means of detecting intracardiac air. ${ }^{32}$

\section{Arterial air embolism}

Coronary and central nervous system vasculature air embolism manifest with ischaemic-type chest pain and acute neurological deterioration respectively, with symptoms of the latter ranging from a sense of doom and altered mental state to focal neurological deficits. Fundoscopy may 
reveal retinal arterial bubbles. Small emboli to other organs are generally well tolerated. ${ }^{8}$

\section{Treatment of air embolism}

When air embolism is suspected, further air entry into the vasculature must be prevented.

Standard cardiopulmonary resuscitation is offered in cases of cardiovascular and respiratory collapse and inotropic support may be required.

Oxygenation with high flow rates is recommended in order to reverse ischaemia and reduce the air bubble size via nitrogen resorption (this applies to both venous and arterial air embolism)..$^{3 .}$

\section{Venous air embolism}

The Trendelenberg or left lateral positioning of the patient with an 'air lock' obstructing the right ventricular outflow tract, may be useful as this may displace the air bubble to a more buoyant position in the right ventricle and allow blood to flow dependent to the air bubble. ${ }^{34}$

Air aspiration from the right ventricle via an already-established central venous catheter has been described, but it is thought that the benefit of this manoeuvre is limited. ${ }^{10}$

\section{Arterial air embolism}

The flat supine position is recommended for 2 reasons: first the pressure haemodynamics of the left ventricle appear to outweigh the effect of attempting to displace the air bubble via Trendelenberg positioning; and second, in the event of cerebral air embolism, cerebral oedema is aggravated by the head-down position. . $^{35,36}$

Cerebral air embolism may present with seizures, and therapy with benzodiazepines or barbiturates may be required.

Hyperbaric oxygen therapy with $100 \%$ oxygen is advocated for those patients with clinical features of arterial air embolism, in particular cardiopulmonary compromise or neurological deficits, ${ }^{37}$ as it further promotes nitrogen resorption from the air bubble and improves the oxygen supply to the tissues. Benefit is greatest when administered early, but may still be useful up till 30 hours post event. ${ }^{38}$

\section{Conclusion}

Air embolus has always been a recognised hazard within the practice of diagnostic imaging. This is now, more than ever, the case with the advent of the widespread use of pump injectors for intravenous contrast delivery and the increasing use of percutaneous interventions in the lungs.

The different clinical syndromes that are associated with air embolus in the systemic venous (right heart) circulation and the systemic arterial (left heart) circulation, need to be clearly understood in order to diagnose and treat these conditions in the clinical setting. These differences between systemic venous and systemic arterial air embolus have been highlighted, and the diagnosis and treatment, based on the pathophysiological differences between venous and arterial air embolus, have been set out.

1. Yu AS, Levy E. Paradoxical cerebral air embolism from a haemodialysis catheter. Am J Kidney Dis 1997;29:453-455.
2. Halliday P, Anderson DN, Davidson AL, Page JG. Management of cerebral air embolism secondary to a disconnected central venous catheter. $\mathrm{Br}$ J Surg 1994;81:71.

3. Porter JM, Pidgeon C, Cunningham AJ. The sitting position in neurosurgery: A critical appraisal. $\mathrm{Br} \mathrm{J}$ Anaesth 1999;82:117-128.

4. Muth CM, Shank ES. Gas embolism. N Engl J Med 2000; 7:477.

5. Hill BF, Jones JS. Venous air embolism following orogenital sex during pregnancy. Am J Emerg Med 1993;11:155-157.

6. Weissman A, Kol S, Peretz BA. Gas embolism in obstetrics and gynaecology: A review. J Reprod Med 1996;41:103-111.

7. Butler BD, Hills BA. Transpulmonary passage of venous air emboli. J. Appl Physiol 1985;59:543-547.

8. Muth CM, Shank ES. Gas embolism. N Engl J Med 2000; 7:476-482.

9. Berkow R, Fletcher AJ, eds. Merck Manual of Diagnosis and Therapy. 16th ed. Rahway, NJ: Merck Research Laboratories, 1991.

10. Palmon SC, Moore LE, Lundberg J, Toung T. Venous air embolism: a review. J Clin Anesth 1997;9:251257.

11. Ziser A, Adiry, Lavon H, Shupaka. Hyperbaric oxygen therapy for massive arterial air embolism durin cardiac operations. J Thorac Cardiovasc Surg 1999;117:818-821.

12. Arnold BW, Zweiber WJ. Percutaneous transthorracic needle biopsy complicated by air embolism. Am J Roentgenol 2002;178:1400-1402.

13. Ashizawa $\mathrm{K}$, Wantanabe $\mathrm{H}$, Morooka $\mathrm{H}$, et al. Hyperbaric oxygen therapy for air embolism complicating CT-guided needle biopsy of the lung. Am J Roentgenol 2004;182:1606-1607.

14. Tolly Tl, Feldmeier JE, Czarnecki D. Air embolism complicating percutaneous lung biopsy. Am J Roentgenol 1988:150:555-556

15. Omenaas $\mathrm{E}$, Moerkve $\mathrm{O}$, Thomassen $\mathrm{L}$, et al. Cerebral air embolism after transthoracic aspiration with a 0,6 mm (23 gauge) needle. Eur Respir J 1989;2:908-910.

16. Regge D, Gallo T, Galli J, Bertinetti A, Gallino C, Scappaticci E. Systemic arterial air embolism and tension pneumothorax: two complications of transthoracic percutaneous thin-needle biopsy in the same patient. Eur Radiol J 1997; 7:173-175.

17. Cianci P, Posin JP, Shimshak RR, Singzon J. Air embolism complicating percutaneous thin needle biopsy of lung. Chest 1987;92:749-751.

18. Pereira P. A fatal case of cerebral artery gas embolism following fine needle biopsy of the lung. Med J Aust 1993;159:755-757.

19. Kodama F, Ogawa T, Hashimoto M, Tanabe Y, Suto Y, Kato T. Fatal air embolism as a complication of CT-guided needle biopsy of the lung. J Comput Assist Tomogr 1999;23:949-951.

20. Wong RS, Ketai L, Temes L, Follis FM, Ashby R. Air embolus complicating transthoracic percutaneous needle biopsy. Ann Thorac Surg 1995;59:1010-1011.

21. Mokhelesi B, Ansaarie I, Bader M, Tareen M, Boatman J. Coronary artery air embolism complicating a CT-guided transthoracic needle biopsy of the lung. Chest 2002;121:993-996.

22. Moon RE. Gas embolism In: Oriani G, Marroni A, Wattel F, eds. Handbook on Hyperbaric Medicine, Milan, Italy: Springer 1996:229-248.

23. Rubinstein D, Dangleis K, Damiano TR. Venous air emboli identified on head and neck CT scans. $J$ Comput Assist Tomogr 1996;20:559-562.

24. Groell R, Schaffler GJ, Rienueller R. The peripheral intravenous cannula: A cause of venous air embolism. Am J Med Sci 1997;314:300-302.

25. Adams M, Quint DJ, Eldeuk P. Iatrogenic air in the cavernous sinus. Am J Roentgenol 1992;159:189190.

26. Shigekedi I, Tsutomu T, Masayuki G, Takenori Y, Yasumasa K. Iatrogenic venous air embolism caused by CT injector - From a risk management point of view. Radiat Med 2004;22:269-271.

27. Ashizawa K. Question and answer. Am J Roentgenol 2005;185:553.

28. Yamamoto A, Toshiyuki M, Masami T, et al. Assessment of cerebral microembolism during percutaneous radiofrequency ablation of lung tumours using diffusion-weighted imaging. Am J Roentgeno 2004;183:1785-1789.

29. Stoelting RK, Dierdorf SF, eds. Anesthesia and Co-existing Disease. 3rd ed. New York: Churchill Livingstone 1993:194-196.

30. O’Dowd LC, Kelley MA. Air embolism. UpToDate 2004,Version 12.2. www.uptodate.com

31. Orebaugh SL. Venus air emboli: Clinical and experimental considerations. Crit Care Med 1992;20:1169.

32. Gildenberg PL, O'Brien RP, Britt WJ, Frost EA. The efficacy of Doppler monitoring for the detection of venous air embolism. J Neurosurg 1981;54:75-78.

33. Van Liew HD, Conkin J, Burkard ME. The oxygen window and decompression bubbles: estimates and significance. Aviat Space Environ Med 1993;64:859-865.

34. Raskin JM, Benjamine E, Iberti TJ. Venous air embolism: Case report and review. Mt Sinae J Med 1985;52:367.

35. Workshop Panel. Final summary of recommendations: diving accident workshop 1990. In: Bennett PB, Moon RE, eds. Diving Accident Management. Bethesda, Md.: Undersea and Hyperbaric Medical Society,1990:366-369.

36. Moon RE, Dear GL, Stolp BW. Treatment of decompression illness and iatrogenic gas embolism. Respir Care Clin N Am 1999;5:93-135.

37. Leach RM, Rees PJ, Wilmshurst P. ABC of oxygen: Hyperbaric oxygen therapy. BMJ 1998;317:1140.

38. Armon C, Deschamps C, Adkinson C, Fealey RD, Orszulak TA. Hyperbaric treatment of cerebral air embolism sustained during an open-heart surgical procedure. Mayo Clin Proc 1991;66:565-571. 